Euskal ikerketen aldizkaria | Revue d'études basques |

Revista de estudios vascos | Basque studies review

Numéro spécial 3 | 2015

Euskal hizkera eta dialektoak gaur egun

\title{
Azkaingo izenordainak
}

\section{Maitena Duhalde}

\section{OpenEdition}

Journals

Édition électronique

URL : http://journals.openedition.org/lapurdum/2652

DOI : 10.4000/lapurdum.2652

ISSN : 1965-0655

Éditeur

IKER

Édition imprimée

Date de publication : 1 novembre 2015

Pagination : 115-123

ISBN : 9782955341322

ISSN : $1273-3830$

Référence électronique

Maitena Duhalde, «Azkaingo izenordainak », Lapurdum [Linean], Numéro spécial 3 | 2015, Sarean emana----an 12 juillet 2017, kontsultatu 22 avril 2019. URL : http://journals.openedition.org/ lapurdum/2652 ; DOI : 10.4000/lapurdum.2652 


\section{Azkaingo izenordainak}

Maitena DUHALDE

UPPA-IKER, UPV/EHU

\section{Laburpena}

Lapurdi itsas hegiko euskara edo «Kostatar» mintzairari buruz gure ezagutzen aberasteko helburuarekin, hizkera honen barne den Azkaine herriko izenordainei interesatu gara. Lan xume honetan, Azkaingo ahozko euskaran erabili ohi diren pertsona izenordain arruntak eta indartuak, baita izenordain zehaztugabeak ere ekarri ditugu. Datu hauek, dialektologian usaiakoak diren irizpideen bidez hautatu lekukoen ahotik bildu dira, inkesta zein hizketa librean. Elementu hauek inguruko hizkerekin alderatu ditugu, gure esku diren lanak kontuan hartuz. Gainera, XVIII, XIX eta XX. mendeetako hiru azkaindarren idatziak aintzat hartu ditugu, hauek dira Michel Chourio, Etienne Lapeyre eta Jean Elissalde, tokiko euskararen bilakaeraren berri eman ahal izateko.

\section{Sar-hitza ${ }^{1}$}

Lan hau hasteko, Pierre Urte, lehen euskal gramatika ezagunaren idazlearen hitzak ekarriko ditugu:

De Toute la Cantabrie francoise où l'on parle le meilleur basque c'est dans la prouince de Labour, qu'on nomme Laphurdi, et surtout a St Jean de Luz et a Sara deux paroisses de cette prouince distantes de deux petites lieues l'une de l'autre c'est ce que tout le monde auoue unanimement en ce païs la. (Urte 1712 [1900]: 5).

Lapurtera klasikoa, prestigiozko mintzaira hau, geografikoki Sara eta Donibane Lohizuneren artean mugatua zen (Oyharçabal 2001: 219). XVIII. mendeak tradizio lapurtar honen beherakada markatzen du eta behe-nafarreraren eragina azkartuko da (Pikabea 1993: 288). Gaur egun, Lapurdi itsas hegiko hizkerak hein batean bere prestigioa eta maiz bere presentzia ere galdu dituela anitzek badakigu.

1. Eskerrak Iñaki Caminori lan honi ekarri oharrentzat. Milesker Azkaingo lekukoei, bereziki Ttotte Errandoneari, haien laguntzarentzat eta pazientziarentzat. 
Kostatarrari, hau da, Lapurdi itsas hegiko mintzoari buruzko lanak urri dira, nahiz eta interes berezikoak ere izan. Hala ere, dialektologoek hizkera honen nortasuna agerian eman dute. XIX eta XX. mendeetan, Louis Lucien Bonapartek eta ondotik Julien Vinson eta Pedro de Yrizarrek, Lapurdi itsasaldeko euskara, lapurteraren azpieuskalki bezala kontsideratu zuten. Gaur egun, Koldo Zuazok nafar-lapurtera euskalkian sartaldeko eta sortaldeko azpieuskalkiak bereizten ditu, eta lehen honen barnean kostatar hizkera agerian ematen du, nafar-lapurtera eta erdialdeko euskararen arteko lotura egiten duela gehituz.

Kostatar mintzairari buruz gure ezagutzen aberasteko gogoarekin, duela hilabete batzuk, hizkera honen barne den Azkaingo herriko erakusleei buruz ohar zenbait ekarri genituen (Duhalde: in press). Inkestak herri berean segituz, aldi honetan Azkaingo izenordainei buruzko datu batzuen ekartzera gatoz.

Aipatuko ditugun datuak, dialektologian usaiakoak diren irizpideen bidez hautatu lekukoen ahotik bildu ditugu, inkesta zein hizketa librean. Elementu hauek inguruko hizkerekin alderatu ditugu, gure esku diren lanak kontuan hartuz. Gainera, XVIII, XIX eta XX. mendeetako hiru azkaindarren idatziak begiratu ditugu, tokiko euskararen bilakaera ere aztertu ahal izateko: Michel Chourioren Jesu-Christoren Imitacionea (1720), Etienne Lapeyreren Kredo edo sinhesten dut esplikatua (1891), Jean Elissalderen Azkaine gure sorterria (1952-1957).

\section{Pertsona izenordainak}

\subsection{Pertsona izenordain arruntak}

Hona izenordain arruntak nola agertzen diren Azkainen, kasuen arabera sailkaturik:

\begin{tabular}{|c|c|c|}
\hline Absolutiboa & ni & i \\
\hline Ergatiboa & nik \\
\hline Datiboa & neri & iri \\
\hline Genitiboa & nere & ire \\
\hline Destinatiboa & neretzat & iretzat \\
\hline Soziatiboa & nerekin & irekin \\
\hline Instrumentala & nitaz & itaz \\
\hline Inesiboa & neregan, nere gañan, nere baitan & iregan, ire gañan, ire baitan \\
\hline Adlatiboa & nereganat, nere baitarat & ireganat, ire baitarat \\
\hline Hurbiltze adlatiboa & neri buruz & iri buruz \\
\hline Ablatiboa & neretaik, nere baitaik, nereganik & iretaik, ire baitaik, ireganik \\
\hline
\end{tabular}




\begin{tabular}{|c|c|c|}
\hline Motibatiboa & neregatik & iregatik \\
\hline$z u$ & $\mathrm{gu}$ & zuek \\
\hline zuk & guk, guek & zuek \\
\hline zuri & guri, gueri & zueri \\
\hline zure & gure, guen & zuen \\
\hline zuretzat & guretzat, guentzat & zuentzat \\
\hline zurekin & gu(r)ekin & zuekin \\
\hline zutaz & gutaz, guetaz & zuetaz \\
\hline zuregan, zure gañan, zure baitan & $\begin{array}{l}\text { gu(r)e (n)gan, } \\
\text { gu(r)e(n) gañan, } \\
\text { gu(r)e(n) baitan }\end{array}$ & $\begin{array}{c}\text { zuengan, zuen gañan, zuen } \\
\text { baitan }\end{array}$ \\
\hline zureganat, zure baitarat & gureganat, guenganat & zuenganat, zuen baitarat \\
\hline zuri buruz & $\begin{array}{l}\text { guri buruz, gueri } \\
\text { buruz }\end{array}$ & zueri buruz \\
\hline zuretaik, zure baitaik, zureganik & $\begin{array}{c}\text { gu(r)etaik, } \\
\text { gu(r)e(n) baitaik, } \\
\text { gu(r)e(n)ganik }\end{array}$ & zuetaik, zuen baitaik, zuenganik \\
\hline zuregatik & guregatik, guengatik & zuengatik \\
\hline
\end{tabular}

Aitzineko testuetan, singularreko lehen pertsonan, ene dugu eta berriagoetan nere eta ene formak ditugu. Izan ere, M. Chourio eta E. Lapeyrek ene dute: enetçat (Chourio 1978: 237), enequiñ (237), ene (Lapeyre 1982: 187) ene gatik (188). Zerbitzarik berriz, bi formak erabiltzen ditu: nere (98), ene (59).

Hizketa librean egin grabaketetan nere entzun dugu beti, nahiz eta Azkaingo lekukoek ene forma ezagutzen duten. XX. mende bukaeran, nere bildu zuen K. Artolak, baita kostatarra osatzen duten bertze herrietan ere: Hendaian nere (Yrizar 1997: 257), Ziburun nèe (268), Donibane Lohizunen ne (269), nahiz Getarian neré, nerí (330). Denboran urrunago joanez, XIX. mendean, L.L. Bonapartek Donibane Lohizunen nere eta ene bildu zituen, baita Sarako 
euskaran ere; Ahetzen eta Ainhoan aldiz, ene baizik ez (BDV m/s Bv. $75^{2}$ ). Lapurdin barnerago den Larresoroko hizkeran, "edute genitiboko nere aski arrunta [dela]" dio tokiko mintzaira aztertu duen Irantzu Epeldek (2003: 115), baina ene ohikoagoa dela zehazten du eta honen gainean eraiki direla eratorriak: enetako \& enetzat, enekin \& enekilan, enegan, bertzeak bertze.

K. Zuazoren sailkapena kontuan hartuz, nafar-lapurteraren sartaldeko azpieuskalkian, destinatiboan, -tzat morfema dugu eta soziatiboan berriz -kin. Morfema orokor hauekin batera, sortaldekoan -etako eta -kilan aldaerak ere ezagunak dira, Uztaritze eskualdetik ekialdera. Ez da harritzekoa beraz, kostatarraren barne den Azkaingo herrian lehen bi aldaeren biltzea, lekukoen ahotik, bai idazleen eskutik: enetçat (Chourio 1978: 237), zuretzat (Lapeyre 1982: 126), guretzat (Elissalde 1985: 33), enequiñ (Chourio 1978: 237) zurekin (Lapeyre 1982: 137).

Ahoskeraz bi hitz errateko, kostatarrak $i$ bokala eta $j$ bokalerdiaren asimilazio bustidura baduela badakigu (Zuazo 2014: 144). Hala ere, soziatiboko -kin morfeman palatalizazioa ez da sistematikoa, izan ere, bustidurarekin zein gabe entzun dugu lekuko beraren ahoan.

Lapurtar idazleek XVIII. mendea arte bustidura irudikatu dutela zehazten du Josu Pikabeak (1993: 40-41). Haren hitzetan, ondoko mendetik goiti, Léonce Goyhetche urruñarrak salbu, Lapurtar idazleek ez dute palatalizazioa adieraziko (41).

K. Zuazok /u + a, e, o/ arteko - b- epentesia Euskal Herri erdiguneko eremu murritzeko ezaugarrien artean sailkatzen du (2014: 218). XIX. mendean Bonapartek -uba- emaitza bildu zuen kostatarra osatzen duten zenbait herritan (BDV m/s Bv 84). Gainera, bere eskuizkribuetan Donibane Lohizuneko zubek, zubetaz, zuberi izenordainen berri ere ematen digu (BDV m/s Bv75). Gure grabaketetan berriz, ez dugu - $b$ - epentetikorik bildu ez Azkainen ez eta Lapurdi itsas hegiko bertze herrietan ere (Duhalde: 2015).

Pluraleko lehen pertsonarentzat, Azkaingo lekukoen ahotik bi sail bildu ditugu, alde batetik, guk eta eratorriak eta bertzetik, guek eta eratorriak. Lehen formak erabiltzen dira literaturan: guri (Chourio 1978: 55), gutaz (Lapeyre 1982: 253), gure (Elissalde 1985: 33). XIX. mendean Donibane Lohizuneko euskaran ere gure dugu genitiboan (BDV m/s Bv75).

Entzun ditugun bigarren forma horiek, pluraleko bigarren pertsona bezala eraikiak dira: guek, gueri, guen, guentzat, eta abar. Ziburun, forma hauez gain, singularreko bigarren pertsonan ien, ientzat ere aditu ditugu. Hauen erabileraren maiztasuna eta zabalera argitzea espero dugu gure hurrengo azterketetan.

2. BDV m/s Bv.75: L.L. Bonaparteren euskal eskuizkribuak, 2C2 mikrofilma (Arana, J. A. \& Gonzalez, C. 1989: 42). 


\subsection{Pertsona izenordain indartuak}

Hona Azkaingo pertsona izenordain indartuak, kasuen arabera taula batean emanik:

\begin{tabular}{|c|c|c|c|c|}
\hline & abs. & erg. & dat. & edute-gen. \\
\hline 1.p.sg. & neone & neonek & neoni & neonen \\
\hline 2.p.sg. & ione & ionek & ioni & ionen \\
\hline 1.p.pl. & geone, guone & geonek, guonek & geoni, guoni & geonen, guonen \\
\hline 2.p.sing. & zeone, zuone & zeonek, zuonek & zeoni, zuoni & zeonen, zuonen \\
\hline 2.p.pl. & - & - & - & - \\
\hline
\end{tabular}

Xiberotik Lapurdi ekialderaino nihaur saileko izenordain indartuak entzuten dira (Zuazo 2014: 136), Uztaritze eskualdean neroni eta nihaur lehiakide dira (Epelde 2003: 115), eta mendebaldean neroni nagusitzen da. Sartaldeko hizkeretan bezala, Azkainen ere neroni sailekoak ditugu.

L.L. Bonapartek ere Donibane Lohizuneko euskaran sail honetako izenordain indartuak bildu zituen: abs. neoni, heoni, geoni. Baita Saran ere: neoni, neonik, neoniri (BDV m/s Bv75). Kostatarrarekin mugan diren Irun eta Hondarribiko euskaran neuni eta geuni formak aditzen dira (Sagarzazu 2005: 72).

Mikel Martínez-Aretak, izenordainen eraketaren prozesuen berri ematen digu, alde batetik izenordain neutroena, $1^{\text {st }}$ PPSP + adverbial haur, eta bertzetik lehen eta bigarren izenordain pertsonalen atzizki prozesua, $2^{\text {nd }}$ PPSP $+1^{\text {st }} \mathrm{p}$. haur, hon-ek / $2^{\text {nd }} \mathrm{p}$. hori, horr-ek (2013: 306-307):

First comes the pronoun, then haur, interpreted as an adverbial element of proximity (hence its lack of inflection, as is the case in the $2^{\text {nd }}$ PPSP) and unspecified for $1^{\text {st }}$ or $2^{\text {nd }} p$., and finally, attached to the result of the $1^{\text {st }}$ PPSP (in its bare form), hau(r) for $1^{\text {st }} p$. and hori for $2^{\text {nd }} p$. pronouns. These are interpreted as demonstratives, and as such are inflected (Martínez-Areta 2013: 307).

Gure idazleek neroni sailekoak darabiltzate: abs. neroni (Chourio 1978: 282), erg. neronek (Elissalde 1985: 98), erg. neronec eta nerorrec (Chourio 1978: 239, 242) abs. ceroni (Chourio 1978: 104), erg. zeronek (Lapeyre 1982: 70), erg. gueronec (Chourio 1978: 72). Datiboaren kasuan, lapurtar idazleek neroni, neroniri eta nerorriri baliatzen dituztela zehazten du J. Pikabeak. Izan ere, kasu absolutiboan erabili ohi den neroni izenordaina, Axularrek kasu datibo gisa dakar (1993: 215). Ziburuko Etxeberriren obran, bi formak ditugu, zerori / zeroni eta zeronek / zerorrek, "non bi sailok, -oni / -ori, -onek / orrek, ez baitute deus ere bereizten" (Azkarate \& Altuna 2001: 35). 
Absolutiboan -i hori ez da agertzen bildu ditugun datuetan, baizik eta -e, datiboarekin nahasketa saihestuz: neone, ione, zeone, geone. Aipatzekoa da ere, zerone eta gerone izenordain indartuez gain, guone eta zuone formak bildu ditugula, baina *nione aldiz ez.

Izenordain indartuez gainera, Iñaki Caminok, singularreko lehen eta bigarren pertsonen izenordain hanpatuak, genitiboan bihurkari ere direnak, neure eta (h)eure, lehen testuetatik Euskal Herriko mendebaldean, erdialdean eta Ipar Euskal Herri gehienean ageri direla seinalatzen du, hedatze horrek forma aski zaharrak direla erakusten duelarik (2008: 119). Hona zer dioen Mitxelenak heure izenordain hanpatuaren jatorriaz: La forma protovasca debió de ser *hi-haur-e, o *hi-hor-e lit. 'de este, ese, tú' (1990: 210).

Neure izenordain bihurkaria darabil M. Chouriok: Nola neure burua iasan deçaquet bizitce dohacabe hunetan? (1978: 191). E. Lapeyre eta J. Elissalderen idazkietan ez ditugu forma horiek irakurri. Gure grabaketetan, hizketa librean adibide urri bildu ditugu eta singularreko lehen pertsonan bakarrik.

\subsection{Izenordain zehaztugabeak}

Hona hemen Azkaingo izenordain zehaztugabeak, taula batean sailkaturik:

\begin{tabular}{|c|c|c|c|c|}
\hline & -bait & edo- & -nahi & neh- \\
\hline \multirow[t]{3}{*}{ izord. } & norbait & - & nornai & nior \\
\hline & zerbait & - & zernai & - \\
\hline & zonbait, zenbait & edozoñ, edozeñ & - & \\
\hline \multirow[t]{3}{*}{ lekua } & nunbait & - & nunai & niun \\
\hline & nuapa(i)t & - & nunaitik & niundik \\
\hline & & & & niorat \\
\hline denbora & noizpait & - & noiznai & - \\
\hline modua & nolazpait & - & nolanai(zka) & - \\
\hline
\end{tabular}

Nabarmentzekoa da bigarren osagaia nahi duten izenordainak nagusi direla: nornai, zernai, nunai; eta edo- duenaren adibide bakarra dugu: edozoñ edo edozeñ. Azkaingo idazleek ere forma berdinak erabili dituzte. Ondoko adibideak M. Chouriorenak dira: nor nahi (1978: 362), cer nahi (206), non nahi (175), norat nahi (175) eta edo ceiñ (39). Lapurdi barnealderago kokatuak diren Larresoroko eta Beskoitzeko herrietan ere, izenordain zehaztugabe gehienak nahi dutenak dira (Epelde 2003: 117; Duhau 2003: 200-202). 
Xiberoan, Erronkarin, Zaraitzun, Behe Nafarroan eta Lapurdi barnealdean, zoin, zonbat, zonbait berriak sortu dira, zein, zenbat eta zenbait ordezkatuz (Camino 2011: 123). M. Chouriok, E. Lapeyrek, baita J. Elissaldek ere, zenbait darabilte: cembait (Chourio 1978: 458), zenbait (Lapeyre 1982: 89; Elissalde 1985: 78). Gure datuei begira, argi da gaur egun Azkainen zenbait eta zonbait izenordainak lehian direla.

I. Caminok zehazten duenez, Behe-Nafarroan eta Lapurdin ne(h)or berrikuntza ibiltzen da, baita Amikuzen ere nihur eta nehor (2011: 103-104). Ekialdean berriz, *e-nor zaharraren ordain zuzenak ditugula dio Zuberoan eta Erronkarin, ïhür \& ïhün, eür \& eur aldaerak, hurrenez hurren. Zaraitzun, Aezkoan eta hego-nafarreran, yor eta yon ditugu. Bertze eremuetako, iñor eta iñon aldaerak, "hein batez egoera zaharraren jarraitzaile dira" (Camino 2011: 104).

Orain arte aipatu ditugun Azkaingo idazleek nihor darabilte, nahiz eta Lapeyrek nehork (158) behin idazten duen. Nihun dute E. Lapeyrek eta J, Elissaldek, nihon berriz M. Chouriok (90). Gaurko azkaindarrek forma berak dituzte, hasperena gabe: nior eta niun.

\section{Ondorio gisa}

Osatzea merezi duen lan honetan, Azkaingo izenordain arrunten, indartuen eta zehaztugabeen berri ematen entseatu gara, guk bildu datuez gain, tokiko idazleak eta orain arte publikatu ikerlanak ere aintzat hartuz.

Oroitaraz dezagun Azkaingo euskaran hasperena eta - $b$ - epentetikoa, biak galdu direla, baita kostatarra osatzen duten bertze herrietan ere; ez dugu beraz, zubek bezalakorik entzun. Izenordain arrunten artean, XVIII. eta XIX. mendeetan ene izenordaina erabiltzen zuten M. Chouriok eta E. Lapeyrek, baina J. Elissaldek nere eta ene, biak lehian. Gaur egun ahozkoan ene baztertu da Azkainen eta inguruko herrietan, ekialderagoko hizkeretan aldiz, gordetzen dute.

Lapurdi eta Behe Nafarroak nehor eta nehon berriak partekatzen dituzte, baita bigarren osagaia nahi- duten izenordainak ere. Indartuetan berriz, sail ezberdinak badira eta Uztaritzetik 
mendebaldera neroni dugu, ekialdeak nihaur duelarik. Hala ere, nahiz eta Azkaingo idatzietan zenbait beti agertu, ekialdeko eragina sumatzen da, gaur egun azkaindarrek zenbait eta zonbait baliatzen baitituzte.

Aldaera iduriz berriak ere bildu ditugu gaurko hiztunen ahotik, hala nola absolutiboan -e bukaerako izenordain indartuak: neone, zeone, geone. Ahantzi gabe guk izenordain arruntarekin lehian den guek aldaera baita geone eta zeone-ren ondoan guone eta zuone formak ere.

\section{Erreferentziak}

Arana, José Antonio \& González, Carlos. 1989. L.L. Bonaparte: eskuizkribuak argitarapenak= manuscritos-publicaciones. Bilbo: Euskaltzaindia \& Azkue Biblioteka.

Azkarate, Miren \& Altuna, Patxi. 2001. Euskal morfologiaren historia. Donostia: Elkarlanean.

Bonaparte, Louis Lucien. (XIX. mende erdia). Contestaciones a cuestionarios dialectológicos en el País Vasco-Francés. Notas referentes a Ahetze, Ainhoa, Arbonne, Arcangues, Armendarits, Aroue et Etcharry, Ascain, Ayherre, Bardos, Bassussarry, Bidart, Bonloc, Cambo, Baïgorry, Briscous, Espelette, Guéthary, Hasparren, Hélette, Iholdy, Irissarry, Isturits, Itxassou, Lahonce, Larressore, Louhossoa, Macaye, Mendionde, Mouguerre, Saint-Esteben, SaintJean-de-Luz, Saint-Jean-Pied-de-Port (Baissassarry), Saint-Martin (Méharin), Saint-Palais, Saint-Pée, Saint-Pierre-d'Irube, Sare, Tardets, Urcuit, Urrugne, Ustaritz, Villefranque, argitaratu gabeko 30. eskuizkribua, BDV m/s Bv 75 .

Bonaparte, Louis Lucien. (XIX. mende erdia). Phonologie de la langue basque dans tous ses dialectes, comprenant les règles de la prononciation, de l'accent tonique et du changement des lettres; suivie de la loi de l'affinité ou harmonie des voyelles, et précédée d'une nouvelle classification des dialectes, sous-dialectes et variétés de l'euskara. D'après de nombreux renseignements pris sur les lieux en 1856, 1857, 1866 et 1867. Argitaratu gabeko 16. eskuizkribua, BDV m/s Bv 84 .

Camino, Iñaki. 2008. Nafarroa Behereko euskara zaharra. ASJU 42. 101-170.

Camino, Iñaki. 2011. Ekialdeko euskararen iraganaz. In Epelde, Irantzu (arg.) Euskal dialektologia: lehena eta oraina. ASJUren gehigarriak LXIX. 87-153.

Chourio, Michel. 1978 [1720]. Jesu-Christoren Imitacionea. 1788. urteko edizioaren faksimilea. Donostia: Hordago.

Duhalde, Maitena. 2015. Lapurdi itsas hegiko euskara: hiru ezaugarri fonologikoren azterketa. I. Ikergazte Nazioarteko ikerketa euskaraz: Kongresuko artikulu-bilduma, Udako Euskal Unibertsitatea. 101-107.

Duhalde, Maitena. (in press) Azkaingo erakusleak. Lapurdum.

Duhau, Henri. 2003. Hasian hasi. Beskoitzeko euskara (Beskoitzeko heskuara). Donibane Lohizune: Euskal Kultur Erakundea \& Beskoitze.

Elissalde, Jean. 1985 [1952-1957]. Azkaine gure sorterria. Donostia: Elkar.

Epelde, Irantzu. 2003. Larresoroko euskara (Dialektologia azterketa). Doktorego tesia, UPV/EHU. 
Lapeyre, Etienne. 1982 [1891]. Kredo edo sinhesten dut esplikatua. L. Villasanteren argitalpena. Bilbo: Euskaltzaindia.

Martínez-Areta, Mikel. 2013. Demonstrative and Personal Pronouns. In Martínez-Areta, Mikel (arg.) Basque and Proto-Basque: Language-Internal and Typological Approaches to Linguistic Reconstruction. Mikroglottika 5. Berna: Peter Lang. 283-321.

Mitxelena, Koldo. 1990 [1961]. Fonética Histórica Vasca, Donostia: ASJU-ren gehigarriak 4, Gipuzkoako Foru Aldundia.

Oyharçabal. Beñat. 2001. Statut et évolution des lettres basques durant les XVIIème et XVIIIème siècles. Lapurdum 6, 219-287.

Pikabea, Josu. 1993. Lapurtera idatzia (XVII-XIX). Bilakaera baten urratsak. Donostia: Kutxa Fundazioa.

Sagarzazu, Txomin. 2005. Hondarribiko eta Irungo euskara. Irun \& Zarautz: Alberdania, Hondarribiko Udala \& Irungo Udala.

Urte, Pierre. 1900 [1712]. Grammaire cantabrique basque. W. Websterren argitalpena, Bagnèresde-Bigorre.

Yrizar, Pedro. 1997. Morfología del verbo auxiliar labortano (estudio dialectológico). Bilbo: Euskaltzaindia \& Euskal Herriko Unibertsitatea.

Zuazo, Koldo. 2014. Euskalkiak. Donostia: Elkar. 